\title{
Plan de formación en competencias informacionales de la BUZ: cuatro años colaborando con el profesorado en la formación de los alumnos de nuevo ingreso (2009-2012)
}

M.E. Asensio, L. Bordonaba, E. Casanova, E. Escar, A. Novellón, A. Sanz, G. Serrano, J.A. Simón, R. Soriano

Biblioteca de la U.Z. - Subcomisión de Formación en CI. Zaragoza. España

\section{OBJETIVOS}

I. Integrar la oferta formativa de la biblioteca en los planes de educativos de la UZ.

2. Utilizar el modelo de enseñanza virtual, a través del ADD, para llegar a todos los alumnos.

3. Incorporar la actividad formativa en las guías docentes.

\section{METODOLOGÍA}

Diseño y desarrollo de contenidos a través de un grupo de trabajo, la Subcomisión de Formación en $\mathrm{Cl}$.

- Alianza con ADD y coordinadores de grado para su implementación.

- Despliegue en los centros a través de los bibliotecarios formadores.

- Análisis de resultados y evaluación del plan por parte de la Subcomisión $\mathrm{Cl}$.

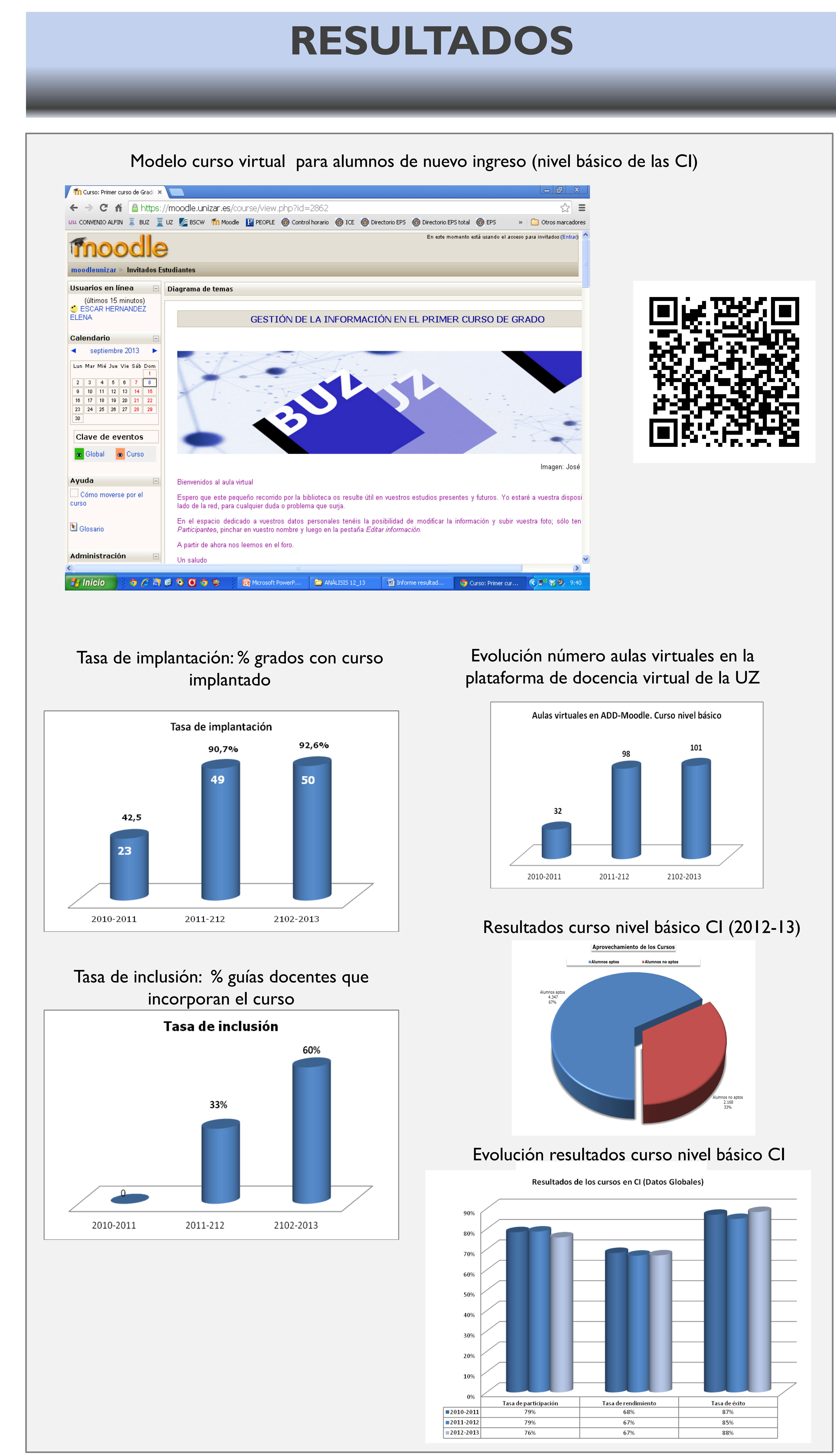

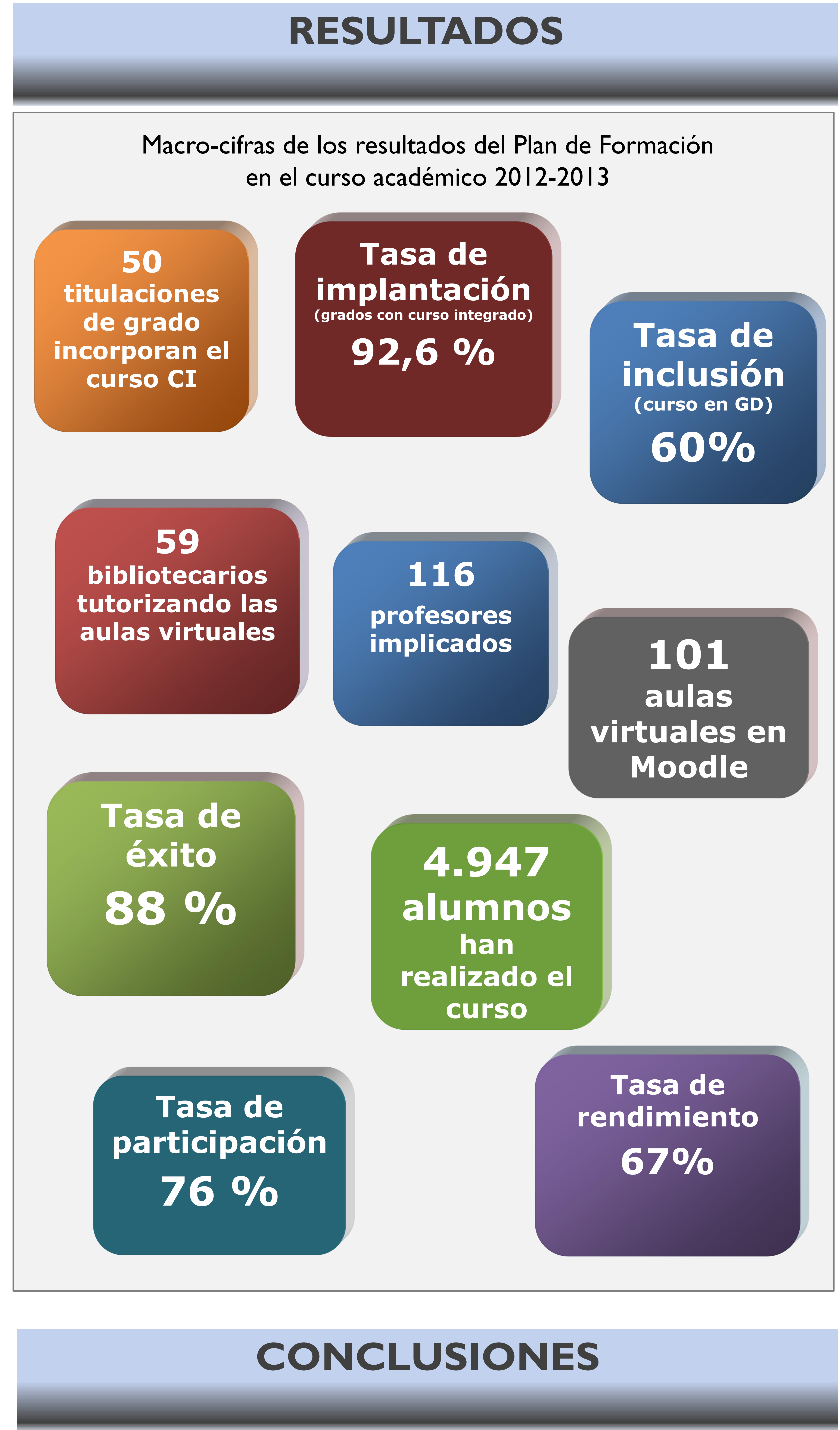

I. La biblioteca, servicio de apoyo a la docencia y al aprendizaje.

2. Colaboración con el profesorado.

3. Actividad de aprendizaje integrada en los plantes de estudio a través de las guías docentes.

4. Alto nivel de satisfacción de todos los agentes implicados.

\section{RETOS}

I. Trabajar hacia las $\mathrm{Cl} 2$, incorporando las competencias informáticas.

2. Desarrollar actividades de aprendizaje para doctorandos, profesorado y otros tipos de usuarios. 